\title{
The Effect of Fire Retardant Composition on Burning Path and Determination of Thermal Resistance of Sawdust for Building Insulation
}

\author{
Muhammad Said ${ }^{\#}$, Muhammad Faizal ${ }^{\#}$ \\ ${ }^{\#}$ Chemical Engineering Department, Faculty of Engineering, Universitas Sriwijaya, Palembang, 30139, Indonesia \\ E-mail:saidm_19@yahoo.com,mfaizal1405@gmail.com
}

\begin{abstract}
Increasing cost of energy requires the application of thermal insulation for the building. Sawdust filled with $\mathrm{CaCO}_{3}$ fire retardant is potential to be applied for building insulation to conserve heat energy across the insulation so that to reduce electrical energy consumption for the building. An apparatus for measuring burning path of sawdust filled with $\mathrm{CaCO}_{3}$ fire retardant has been constructed. Heat flux meter was also constructed to measure thermal conductivity and thermal resistance of the sawdust insulation. The composition of $\mathrm{CaCO}_{3}$ fire retardant in sawdust mixture used in the experiment ranged from $5 \%$ to $30 \%$ and $100 \%$ sawdust was used as a control. The burning path and burning time were measured for each composition of $\mathrm{CaCO}_{3}$ and for the control, as well as, burning velocity was determined. Thermal data of the sawdust insulation was determined for the density of $43.25 \mathrm{~kg} / \mathrm{m}^{3}$ and 64.88 $\mathrm{kg} / \mathrm{m}^{3}$ with a thickness of the insulation from $2 \mathrm{~cm}$ to $8 \mathrm{~cm}$. The burning path, as well as, burning time decreased as the composition of $\mathrm{CaCO}_{3}$ fire retardant increased with the smallest one of $1.25 \mathrm{~cm}$ and 5 minutes achieved for $\mathrm{CaCO}_{3} 30 \%$. The lowest burning velocity was achieved at $\mathrm{CaCO}_{3} 30 \%$. Thermal conductivity and thermal resistance increased with the increase of the thickness of the sawdust insulation. The highest thermal conductivity of $0.553 \mathrm{~W} / \mathrm{mK}$ and the highest thermal resistance of $0.145 \mathrm{~m} / \mathrm{K} / \mathrm{W}$ achieved at $8 \mathrm{~cm}$ thickness of the insulation and density of $43.25 \mathrm{~kg} / \mathrm{m}^{3}$, while at density of $64.875 \mathrm{~kg} / \mathrm{m} 3$, the highest thermal conductivity was $0.398 \mathrm{~W} / \mathrm{mK}$ and the highest thermal resistance of $0.201 \mathrm{~m}^{2} \mathrm{~K} / \mathrm{W}$.
\end{abstract}

Keywords - burning path; burning time; fire retardant; sawdust insulation; thermal conductivity; thermal insulation for building; thermal resistance

\section{INTRODUCTION}

The steadily increasing cost of energy has resulted in economic justification for increased amounts of thermal insulation in the building. High R-values in attics are achieved by installing thick layers of horizontal insulation. The resulting installation of the horizontal insulation is heated from below, and large temperature differences across the insulation can exist. The trend toward thick layers of porous insulation heated from below suggests that the potential for convective heat transfer within the porous insulation be reexamined. The industry generally views heat transport by free convection within the insulation materials to be negligible. The convective transport was negligible when the insulating batts were bounded by solid plates. The standard laboratory test for the thermal resistance (R-value) of the insulations is described in ASTM C 177 and C 518. Both C 177 and C 518 use test specimens that are bounded by solid surfaces. The test is usually performed on specimens that are two to six inches thickness. Insulation materials are being used in a system that has different boundary conditions than the test system, and insulations are being used at a thickness that greatly exceeds the test thicknesses. An apparatus for measuring the thermal data including the apparent thermal conductivities and thermal resistances should be developed to fulfill the boundary conditions and the insulation thicknesses. The phenomenon of natural or free convection through porous media has received increased attention due to the application in both the geophysical field and the thermal insulation field. Natural convection can take place in a porous medium filled with a fluid when the medium is heated from below. Natural or free convection is the heat transfer by the flow of the fluid due to gravity and temperature-induced density variations in the fluid. The criteria for the onset of natural convection in a porous medium is given by the Rayleigh number. Nusselt number is a function of the Rayleigh number, and it is a measure of the degree of convection. When heat transport is due to conduction and radiation, the Nusselt number is equal to one. When the Nusselt number is greater than one, convection is occurring in the porous media. Thermal 
resistance is reduced when the Nusselt number is greater than one.

Application of thermal insulation for the building is to reduce electrical energy consumption required either for the heater in winter season or air conditioning in the hot season and hence reducing the cost of the electrical energy utilization for the building. Application of thermal insulation led to energy efficiency achievement. Using thermal insulation materials for buildings provided advantages, that is energy savings, little capital expenditure for about $5 \%$ of the building construction and reduction of the pollutant emissions [1]. Thermal insulation materials were frequently installed on the roof to reduce the energy consumption of indoor space. Utilization of HVAC (heating, ventilation and air conditioning) in the buildings consume a large energy. The existing energy was retrofitted, as well as; new buildings were designed to achieve energy efficiency improvement. The energy consumption can be lowered by installing the insulation on the roof [2]. Air-conditioning energy consumption was measured for green roofs without thermal insulation and with thermal insulation of the residential building. Block 1 was designed for building without thermal insulation using control, Mexican Sedum and Perennial Peanut while Block 2 was designed for building with thermal insulation using control, Mexican Sedum and Perennial Peanut. Daily energy consumption at Block 1 was $89.24 \mathrm{kWh}$ for control, $67.49 \mathrm{kWh}$ for Sedum and $64.44 \mathrm{kWh}$ for Peanut while that at Block 2 was 67.02 $\mathrm{kWh}$ for control, $54.00 \mathrm{kWh}$ for Sedum and $67.16 \mathrm{kWh}$ for Peanut in summer with sunny weather. Daily energy consumption at Block 1 was $75.31 \mathrm{kWh}$ for control, 66.36 $\mathrm{kWh}$ for Sedum and $66.14 \mathrm{kWh}$ for Peanut while that at Block 2 was $58.83 \mathrm{kWh}$ for control, $52.61 \mathrm{kWh}$ for Sedum and $67.27 \mathrm{kWh}$ for Peanut in summer with cloudy weather. Daily energy consumption at Block 1 was $41.98 \mathrm{kWh}$ for control, 40.01 kWh for Sedum and $37.80 \mathrm{kWh}$ for Peanut while that at Block 2 was $38.15 \mathrm{kWh}$ for control, $36.39 \mathrm{kWh}$ for Sedum and $42.46 \mathrm{kWh}$ for Peanut in summer with rainy weather. Reduction of energy consumption occurred when Sedum and Peanut layer was installed at Block 1. The reduction of the energy consumption also occurred when Sedum layer was applied at Block 2 [3]. Thick layers of the building insulation installed in the roof or walls to obtain higher thermal resistance in order that to reduce the heat flows through roof or wall. Factors should be considered for application of the insulation materials in the design of buildings, that is energy consumption [4], space usage and layout [5], thermal, acoustical and visual, as well as, life cycle [6]. Required U-values for new domestic buildings in the United Kingdom by 2020 for building element wall, floor, roof, and window are smaller than the current Uvalues of 2010 standard. Polymeric foams and inorganic wools were used as insulation materials in the European market. The European market used $60 \%$ inorganic materials and $27 \%$ plastic foams [7]. Plastic foams are used for building insulation since these materials possess lower conductivity, lower density, and small thermal transmittance.

The selection of proper and effective thermal insulating materials requires an understanding of the mechanisms of heat transport with the insulation. Heat transport by radiation and convection should be reduced to obtain a low apparent thermal conductivity. Heat transfer by conduction is generally limited by the thermal conductivity of still air within the insulation. The extrapolation of thermal resistance values based on the value of the thermal resistance of the lower thickness is usually adopted in the design of building using the insulation materials. The design of buildings requires energy efficiency by minimizing thermal transmittance of the building envelope.

Types of porous insulation for the building are widely used such as loose-fill fiberglass and rock wool. Based on analysis of four weighting scenarios, that is: cost, thermal resistance, sustainability or fire performance, the best performer was rockwool [8]. Different insulation materials are available on the market, and these materials are used in the buildings [9]. Insulation materials can be from plants, animals, synthetics or mineral. The structure of the insulation materials can be foamy or fibrous [10]. Improvement of heat insulation performance can be achieved by combining different insulation materials [11]. Development of biomass wastes for thermal insulation for the building is in interest due to the enormous quantity of these materials such as sawdust and wood branches. This biomass contains cellulosic materials that can be developed for building insulation to conserve heat. In South Sumatra, sawdust is by product of wood industry. Sawdust is biomass waste and mounted around the area of the wood industry. It contains cellulosic and hemicellulosic material. Sawdust contains natural fibers which can be used for thermal insulation, acoustic insulation, lower carbon emission and fewer health issues when it compared to the mineral insulation. The natural fibers used as construction material since it provides physical, mechanical and acoustic properties [10], [12]-[13]. Crop by products such as barley and wheat straw and corn were sufficient to be used as natural thermal insulation. Corn by-products were sufficient to insulate between 250.000 and 450.000 dwelling yearly [14]. Study of thermal properties of Ichu fibers showed that thermal conductivity varied from $0.047-0.113 \mathrm{~W} / \mathrm{mK}$ for mats with unidirectionally oriented fibers [15]. Joshi et al. Studied natural fiber composites revealing that natural fiber composites are environmentally superior to glass fiber ones [16]. Development of new insulation materials and technologies are still carried out to achieve a better energy efficiency of building [17]. Energy consumption can be low by using roof in the building [18]. Heat into interior space can be suppressed and delayed by increasing the roof mass structure and the insulation [19]. Micro- and nano-channeled polymer composites had been developed from poly lactic acid (PLA) fiber networks embedded in a high-temperature epoxy matrix. The polymer composites were optimized for both thermal insulation and mechanical properties. Convective heat transfer was limited through the channel due to the reduction of channel diameter from microscale to nano-scale as gas diffusion was constrained by Knudsen effect and hence reducing the thermal conductivities of the composites. As the packing of micro-channels increased from $26 \%$ to $71 \%$, density decreased from $1.27 \mathrm{~g} / \mathrm{cm}^{3}$ to $0.36 \mathrm{~g} / \mathrm{cm}^{3}$, as well as; the thermal conductivity decreased from $278 \mathrm{~mW} / \mathrm{mK}$ to $51 \mathrm{~mW} / \mathrm{mK}$ [20]. Reduction of thermal conductivity of mullite fiber-reinforced aerogel composites was conducted by preparing SiC coatings on surfaces of the 
composites. Effective specific extinction coefficient increased from less than 30.4 to about $56.3 \mathrm{~m}^{2} / \mathrm{kg}$ in the wavelength range of $2.5-7.5 \mu \mathrm{m}$. Thermal conductivities of $\mathrm{Al}_{2} \mathrm{O} 3-\mathrm{SiO}_{2}$ composite reinforced by $\mathrm{SiC}$-coated and uncoated mullite fibers increased as temperature increased from 200 to $1000 \mathrm{oC}$. Thermal conductivities of $\mathrm{Al}_{2} \mathrm{O}_{3}-\mathrm{SiO}_{2}$ composite reinforced by $\mathrm{SiC}$-coated were lower than that of uncoated mullite fibers. The thermal conductivity of $\mathrm{Al}_{2} \mathrm{O}_{3}$ $\mathrm{SiO}_{2}$ composite reinforced by $\mathrm{SiC}$-coated was $0.049 \mathrm{~W} / \mathrm{mK}$ while that of uncoated mullite fibers was $0062 \mathrm{~W} / \mathrm{mK}$ [21]. Upward flame spread phenomenon of thermal insulation materials of extruded polystyrene and polyurethane foams had been observed, and their burning performance was analyzed by capturing heat release rate. The flame spread rate weakened by chars covering outside surface of PU pyrolyzed. The effect of fire retardant of PRU reduced flame height when it was compared with the flame height of PU. Pyrolysis of XPS and RXPS resulted in shrinking and melting of the materials and dropped slowly due to the viscosity effect. The maximum flame height of RPU was around $0.6 \mathrm{~m}$ is lower than $1 \mathrm{~m}$ of PU. Peak heat release of RPU was $38.3 \mathrm{~kW}$ at approximately $75 \mathrm{~s}$ being lower than that of PU of $123.5 \mathrm{~kW}$ at approximately $60 \mathrm{~s}$ [22]. Development of porous thermal insulation materials using fly ash of coal by foaming and slip casting process method had been developed. Effects of foaming agent additives and various sintering temperatures on porosity, compressive strength, and thermal conductivity were studied. The lowest thermal conductivity of the sintered thermal insulation material was achieved $0.0511 \mathrm{~W} /(\mathrm{mK})$ being suitable to be applied for wall insulation [23]. Performance based design methodology was proposed for designing insulation systems in buildings based on the design of thermal barriers for controlling the onset of pyrolysis [24]. Development of natural thermal insulation materials from renewable crop byproducts, namely: rice husk, corn pitch and barley straw and natural binders, namely: corn starch and sodium alginate had been conducted. Analysis of thermal degradation and fire behavior of the natural thermal insulation materials was carried out. Characterization of the crop by-products was conducted by using pyrolysis combustion flow calorimeter (PCFC). PCFC results showed that values of HR $6.5 \mathrm{MJ} / \mathrm{kg}$ and PHRR $67.7(\mathrm{~W} / \mathrm{g})$ for corn pith with corn starch, while values of HR 6.0 MJ/kg and PHRR $61.4(\mathrm{~W} / \mathrm{g}$ ) for corn pith with sodium alginate [25].

The insulation materials derived from the cellulosic ones provides benefits to be developed since these materials are available in the enormous amount of biomass waste. The insulation materials derived from the cellulosic materials are categorized into natural thermal insulation materials. These materials can be obtained from renewable resources, and they are more advantageous compared with thermal insulation derived from petroleum. These materials are composed of organic materials in fiber form or chunks. The cellulosic building insulation can be applied in the building with various configuration based on the requirement for the building. In the application of the insulation materials, thermal and mechanical properties, as well as, chemical properties should be considered. Fiber insulation derived from biomass is used because it is easy to form dimensionally and it provides mechanical strength to the environmental disturbance. One of the waste biomass suitable for the building insulation is sawdust. Application of sawdust for the insulation is supported by its availability as the organic solid waste, and it contains cellulose and hemicellulose. However, it should be mixed with a filler such as fire retardant before it is applied for the building insulation.

Fire retardant is applied to the porous insulation material to improve its characteristics as burning resistance. The fire retardant reduces burning speed and delays the burning process on the material surface. It slows down the combustion reaction since it produces gases that absorb heat. Various fire retardants used such as mono-ammonium and diammonium phosphate, aluminum sulphate, ammonium sulphate, calcium sulphate, boric acid, zinc chloride, calcium carbonate and hydrated alumina, as well as, sulfamic acid salts such as ammonium sulphamate [26].

The addition of fire retardant in the sawdust increases mass or bulk density of the sawdust and retard flame of fire within the material. The composition of the fire retardant in the insulation material determines burning path and burning time within the material. Appropriate composition of the fire retardant should be determined for the optimal usage of the sawdust as building insulation.

The purpose of this research is to determine the composition of the fire retardant providing the shortest burning path, the smallest burning time and to measure thermal conductivity, as well as, the thermal resistance of the sawdust insulation material with different thicknesses and densities of the insulation.

\section{MATERIAL AND METHOD}

\section{A. Measurement of Burning Path and Burning Time of Sawdust}

Apparatus for measurement of burning path of sawdust was constructed. It was constructed using iron metal for bottom and sides except for the upper part of the apparatus being made of glass to view burning path. The size of the apparatus was $30 \times 10 \times 10 \mathrm{~cm}$. The movable plate placed on the bottom of the burning box to store the sample. Calcium carbonate with the composition of $5 \%$ was added into the sawdust and mixed evenly for 30 minutes. Total weight of sawdust and calcium carbonate was $250 \mathrm{~g}$. The sample was placed in the movable disk and burned. Burning process was examined through the glass cover and the burning time was recorded. Measurement of the burning path was conducted using a meter tape after burning completed. The sample was withdrawn from the movable plate, and a new sample of different $\mathrm{CaCO}_{3}$ composition was placed in the movable plate. The burning process was repeated for the sample with the composition of $\mathrm{CaCO}_{3} 10 \%$ up to $30 \%$, as well as, measurements of the burning time and burning path.

\section{B. Thermal Measurement of Polystyrene Board}

The apparent thermal conductivity of the polystyrene board was obtained in the R-Matic. The R-Matic includes a heat-flux meter and temperature controller for the hot plate, cold plate, and air space surrounding a test specimen. The polystyrene board was placed in the chamber which included two temperature controlled horizontal plates. The upper plate 
was stationary, and its temperature was controlled by a refrigerated heat sink. The lower plate could be raised or lowered to allow the polystyrene board to be tested. The temperatures of the two plates are measured using platinum resistance thermometer, and the output was displayed on the front panel of the R-Matic. The thickness of the polystyrene board was measured using a linear motion potentiometer, and its output was also displayed on the front panel. A guard heater was used to reduce heat losses in the directions perpendicular to the heat flow. The amount of heat flowing through the specimen was measured by a sensitive heat flow transducer which had an emf output proportional to heat flow passing through it. The R-matic was designed to test homogeneous installations with conductivities between 0.015 to $0.43 \mathrm{~W} / \mathrm{mK}$. Thermal measurements of polystyrene board specimen with a dimension of $60 \times 60 \times 5 \mathrm{~cm}$ equipped with thermocouples and without thermocouples were conducted in the R-Matic. Type T thermocouples were installed on top of the polystyrene board before thermal measurements were conducted. Thermal measurements were carried out for the polystyrene board specimen without thermocouples and those for the specimen with thermocouples. The polystyrene board with known thermal properties was used as a heat flux meter in the thermal measurement of sawdust insulation.

\section{Thermal Measurement of Sawdust Insulation}

The apparent thermal conductivities and thermal resistances of sawdust insulation were measured using a thermal measurement apparatus as shown in Fig. 1. The apparatus was sized to achieve steady-state one-dimensional heat transfer through a test specimen. The primary design consideration was to provide a specimen size large enough to reduce heat losses from the specimen edges to an acceptable value. Polystyrene board with a dimension of 60 x $60 \times 5 \mathrm{~cm}$ was used as a heat flux meter. Thermocouples were installed on both sides of the board to measure the temperature across the board. The temperature difference across the heat flux meter of known thermal conductivity was used to determine the heat flux.

The heater was installed below the heat flux meter, and glass wool was placed below the heater to reduce downward heat loss. The heat losses from the edges of specimens were reduced by providing a thick layer of polystyrene. Test specimens were heated from below by the heater. The flux was determined by the temperature difference across the polystyrene board. The temperature difference across a test specimen was measured by a thermocouple attached to a screen placed on top of the specimen and a thermocouple positioned above the heat flux meter. The thickness of specimen was measured using a probe.

The apparatus was designed to measure the apparent thermal conductivity of thermal insulation of sawdust at different thicknesses, densities and temperature differences. The sawdust insulation was tested in this study. The apparatus is basically a hollow cube with an open top. A $30 \mathrm{~cm}$ thick layer of polystyrene was used to reduce heat losses in the horizontal direction. Glass wool was placed below the heat flux meter to reduce heat losses. Power through the heater was set by an auto transformer.

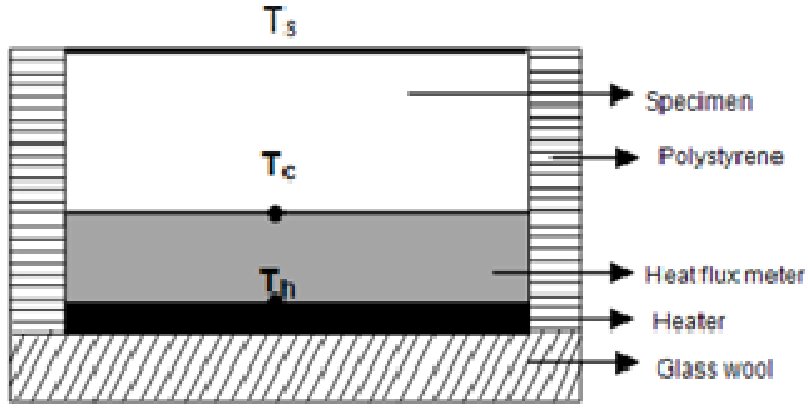

Fig. 1 Thermal measurement apparatus

\section{RESULTS AND DISCUSSION}

\section{A. Burning Path and Burning Time of Sawdust}

Measurement of burning path and burning time were conducted for sawdust containing $\mathrm{CaCO}_{3}$ as fire retardant ranged from 5 to $30 \%$. Burning path with respect to the composition of $\mathrm{CaCO}_{3}$ is shown in Fig. 2. The burning path reduces as the composition of $\mathrm{CaCO}_{3}$ increases. The burning path is $7.5 \mathrm{~cm}$ without $\mathrm{CaCO} 3$ in the sawdust, and it achieves the smallest burning path of $1.25 \mathrm{~cm}$ at $\mathrm{CaCO}_{3}$ $30 \%$. Burning time of sawdust was measured for the composition of $\mathrm{CaCO}_{3}$ ranged from 5 to $30 \%$. Measurement results are shown in Fig. 3. The burning time of sawdust reached 55 minutes at zero percent of $\mathrm{CaCO}_{3}$ and reduced along with the increase of $\mathrm{CaCO}_{3}$ composition. At $30 \%$ composition of $\mathrm{CaCO}_{3}$, it reached 12 minutes burning time.

As the composition of the fire retardant is increased, burning path, as well as burning time is decreased. During the heating process, $\mathrm{CaCO}_{3}$ decomposes endothermically to $\mathrm{CaO}$ and $\mathrm{CO}_{2}$. The product of $\mathrm{CaO}$ forms layers on the sawdust surface that it insulates the layers of the sawdust surface. The release of $\mathrm{CO}_{2}$ reduces the formation of flammable gas, dilution, cooling, and heat absorption, and hence to prevent penetration of fire on the sawdust. Dehydration results in complex reaction of the cellulosic material of the sawdust to form higher cellulosic molecules due to complex bond among the cellulosic molecules. As the structure of the molecules becomes bigger, the cellulosic materials of the sawdust is difficult to burn.

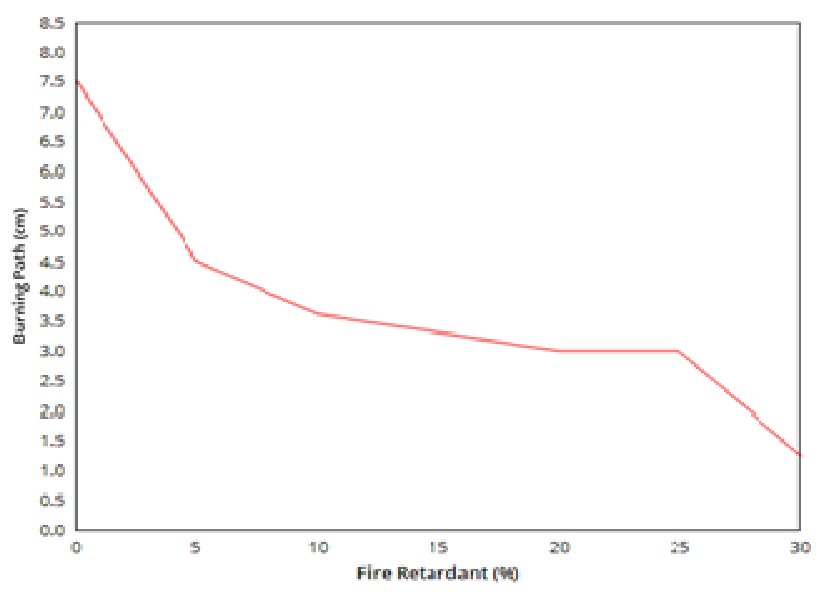

Fig. 2 Burning path with respect to composition of fire retardant 


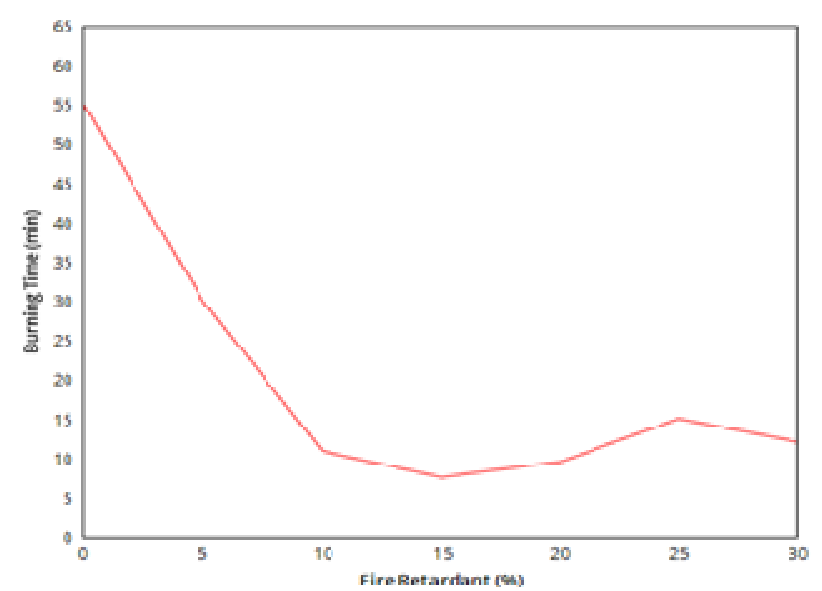

Fig. 3 Burning Time with Respect to Composition of Fire Retardant

\section{B. Apparent Thermal Conductivity of Polystyrene board}

Measurements of the thickness of polystyrene board and heat flux of polystyrene board were conducted in R-matic with various temperatures at the bottom and top of the polystyrene board. The results of the measurement of thickness and heat flux of the polystyrene board were shown in Table 1 and Table 2 for polystyrene board without thermocouples and with thermocouples, respectively. Values of cold and hot temperatures, corrected thicknesses, heat fluxes were used to calculate apparent thermal conductivities of polystyrene board. Measurements of the thickness of the polystyrene board and heat fluxes were carried out at steady state condition.

TABLE I

EXPERIMENTAL RESULTS OF THICKNESS AND HEAT FLUX OF POLYSTYRENE BOARD WITHOUT THERMOCOUPLES

\begin{tabular}{|c|c|c|c|c|}
\hline $\begin{array}{c}\mathbf{T}_{\mathbf{h}} \\
{ }^{\mathbf{o}} \mathbf{C}\end{array}$ & $\begin{array}{c}\mathbf{T}_{\mathbf{c}} \\
{ }^{\mathbf{o}} \mathbf{C}\end{array}$ & $\begin{array}{c}\mathbf{d}_{\mathbf{p}} \\
\mathbf{m}\end{array}$ & $\begin{array}{c}\mathbf{d}_{\mathbf{c}} \\
\mathbf{m}\end{array}$ & $\begin{array}{c}\mathbf{Q} \\
\mathbf{W} / \mathbf{m}^{2}\end{array}$ \\
\hline 35.06 & 10.01 & 0.05057 & 0.05092 & 1.95 \\
\hline 38.30 & 12.60 & 0.05058 & 0.05093 & 2.04 \\
\hline 43.05 & 12.68 & 0.05061 & 0.05096 & 2.43 \\
\hline 45.56 & 15.66 & 0.05061 & 0.05096 & 2.42 \\
\hline 47.65 & 17.73 & 0.05061 & 0.05096 & 2.46 \\
\hline 47.58 & 21.44 & 0.05060 & 0.05095 & 2.16 \\
\hline 49.60 & 22.92 & 0.05059 & 0.05094 & 2.22 \\
\hline 49.82 & 25.85 & 0.05059 & 0.05094 & 2.01 \\
\hline
\end{tabular}

The experimental results for the apparent thermal conductivity of polystyrene board without thermocouples and with thermocouples were shown in Table 3 and Table 4, respectively. The temperature ranged from 35.06 to $49.82{ }^{\circ} \mathrm{C}$ at the bottom of polystyrene board and from 10.01 to 25.85 ${ }^{\circ} \mathrm{C}$ at the top of the polystyrene board without thermocouples while that ranged from 35.37 to $49.63{ }^{\circ} \mathrm{C}$ at the bottom of polystyrene board and from 9.93 to $24.68{ }^{\circ} \mathrm{C}$ at the top of the polystyrene board with thermocouples.
TABLE II

EXPERIMENTAL RESUlts of ThickNess AND HEAT FluX OF POLySTYRENE BOARD WITHOUT THERMOCOUPLES

\begin{tabular}{|c|c|c|c|c|}
\hline $\begin{array}{c}\mathbf{T}_{\mathbf{h}} \\
{ }^{\mathbf{o}} \mathbf{C}\end{array}$ & $\begin{array}{c}\mathbf{T}_{\mathbf{c}} \\
{ }^{\mathbf{o}} \mathbf{C}\end{array}$ & $\begin{array}{c}\mathbf{d}_{\mathbf{p}} \\
\mathbf{m}\end{array}$ & $\begin{array}{c}\mathbf{d}_{\mathbf{c}} \\
\mathbf{m}\end{array}$ & $\begin{array}{c}\mathbf{Q} \\
\mathbf{W} / \mathbf{m}^{2}\end{array}$ \\
\hline 35.37 & 9.93 & 0.04972 & 0.05008 & 1.988 \\
\hline 39.32 & 12.07 & 0.04969 & 0.05003 & 2.160 \\
\hline 40.51 & 15.31 & 0.04970 & 0.05004 & 2.017 \\
\hline 44.44 & 17.14 & 0.04972 & 0.05006 & 2.214 \\
\hline 45.81 & 19.86 & 0.04974 & 0.05008 & 2.123 \\
\hline 47.57 & 21.76 & 0.04974 & 0.05008 & 2.129 \\
\hline 49.81 & 22.90 & 0.04974 & 0.05008 & 2.236 \\
\hline 49.63 & 24.68 & 0.04973 & 0.05007 & 2.080 \\
\hline
\end{tabular}

TABLE III

EXPERIMENTAL RESULTS FOR APPARENT THERMAL CONDUCTIVITY OF POLYSTYRENE BOARD WITHOUT THERMOCOUPLES

\begin{tabular}{|c|c|c|c|}
\hline $\begin{array}{c}\mathbf{T}_{\mathbf{h}} \\
{ }^{\mathbf{o}} \mathbf{C}\end{array}$ & $\begin{array}{c}\mathbf{T}_{\mathbf{c}} \\
{ }^{\mathbf{o}}\end{array}$ & $\begin{array}{c}\mathbf{T}_{\mathbf{m}} \\
{ }^{\mathbf{o}} \mathbf{C}\end{array}$ & $\begin{array}{c}\mathbf{k}_{\mathbf{a s}} \\
\mathbf{W} / \mathbf{m K}\end{array}$ \\
\hline 35.06 & 10.01 & 22.54 & 0.03971 \\
\hline 38.30 & 12.60 & 25.45 & 0.04040 \\
\hline 43.05 & 12.68 & 27.87 & 0.04084 \\
\hline 45.56 & 15.66 & 30.61 & 0.04140 \\
\hline 47.65 & 17.73 & 32.69 & 0.04188 \\
\hline 47.58 & 21.44 & 34.51 & 0.04223 \\
\hline 49.60 & 22.92 & 36.26 & 0.04249 \\
\hline 49.82 & 25.85 & 37.84 & 0.04274 \\
\hline
\end{tabular}

TABLE IV

EXPERIMENTAL RESULTS FOR APPARENT THERMAL CONDUCTIVITY OF POLYSTYRENE BOARD WITH THERMOCOUPLES

\begin{tabular}{|c|c|c|c|}
\hline $\begin{array}{c}\mathbf{T}_{\mathbf{h}} \\
{ }^{\mathbf{0}}\end{array}$ & $\begin{array}{c}\mathbf{T}_{\mathbf{c}} \\
\mathbf{o}\end{array}$ & $\begin{array}{c}\mathbf{T}_{\mathbf{m}} \\
\mathbf{o}^{\mathbf{C}}\end{array}$ & $\begin{array}{c}\mathbf{k}_{\text {as }} \\
\mathbf{W} / \mathbf{m K}\end{array}$ \\
\hline 35.37 & 9.93 & 22.65 & 0.03914 \\
\hline 39.32 & 12.07 & 25.70 & 0.03969 \\
\hline 40.51 & 15.31 & 27.91 & 0.04009 \\
\hline 44.44 & 1714 & 30.79 & 0.04063 \\
\hline 45.81 & 19.86 & 32.84 & 0.04100 \\
\hline 47.57 & 21.76 & 34.67 & 0.04136 \\
\hline 49.81 & 22.90 & 36.36 & 0.04165 \\
\hline 49.63 & 24.68 & 37.16 & 0.04178 \\
\hline
\end{tabular}

The apparent thermal conductivities of polystyrene board with and without thermocouple were designated with curve a1 and a1, respectively as shown in Fig. 4. Differences of the apparent thermal conductivity of the polystyrene board without and with thermocouples is from 1.7 percent to 2.1 percent. The difference is not, however, statistically significant since the uncertainty of the R-Matic 
measurements is \pm 3 percent. The apparent thermal conductivity of the polystyrene board without and with thermocouples increases along with the average temperature of the polystyrene board $\left(\mathrm{T}_{\mathrm{m}}\right)$.

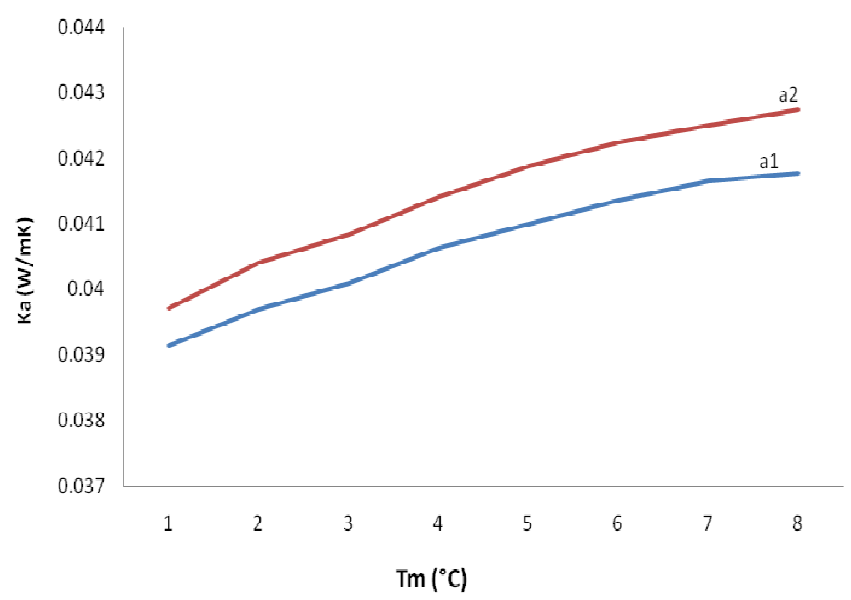

Fig. 4 Apparent thermal conductivities with respect to average temperature of polystyrene board

Based on the least square fits, the correlation of $\mathrm{k}_{\mathrm{as}}$ values with respect to mean temperatures is given by Equation (1) and Equation (2) for the polystyrene board without and with thermocouples, respectively. Percent deviation of the equation from the experimental $\mathrm{k}_{\mathrm{as}}$ is \pm 0.2 percent and \pm 0.01 percent for the polystyrene boards with and without thermocouples, respectively.

$$
\begin{aligned}
& \mathrm{k}_{\mathrm{as}}=0.035295+0.19909 \times 10^{-3} \mathrm{~T}_{\mathrm{m}} \\
& \mathrm{k}_{\mathrm{as}}=0.034953+0.18442 \times 10^{-3} \mathrm{~T}_{\mathrm{m}}
\end{aligned}
$$

Equation (2) was used to determine the apparent thermal conductivity of the polystyrene board used as a heat flux meter since it was equipped with the thermocouples to measure the temperature at both sides of the polystyrene board and hence the apparent thermal conductivity of the polystyrene board. The values of $k_{a s}$ were used to determine heat fluxes across the polystyrene board.

\section{Apparent Thermal Conductivity of Sawdust}

Thermal data for the apparent thermal conductivity of sawdust, $k_{a}$, was measured for two bulk densities, $\rho_{1}$ and $\rho_{2}$, that is $43.250 \mathrm{~kg} / \mathrm{m}^{3}$ and $64.875 \mathrm{~kg} / \mathrm{m}^{3}$ as shown in Fig. 5 . The thickness of sawdust ranges from 2 to $8 \mathrm{~cm}$. The values of the apparent thermal conductivity increase with the increase of the thickness of sawdust for both bulk densities. Measured values of $\mathrm{k}_{\mathrm{a}}$ range from 0.145 to $0.553 \mathrm{~W} / \mathrm{mK}$ at $\rho_{1}=43.250 \mathrm{~kg} / \mathrm{m}^{3}$ and they range from 0.113 to 0.398 $\mathrm{W} / \mathrm{mK}$ at $\rho_{2}=64.875 \mathrm{~kg} / \mathrm{m}^{3}$. Lower bulk density provides higher $\mathrm{k}_{\mathrm{a}}$ values due to the air filled porosity of materials so that the convective effect may occur. At higher bulk density, convective effect insignificant due to small porosity. Therefore, $\mathrm{k}$ values are higher at a smaller value of bulk density.

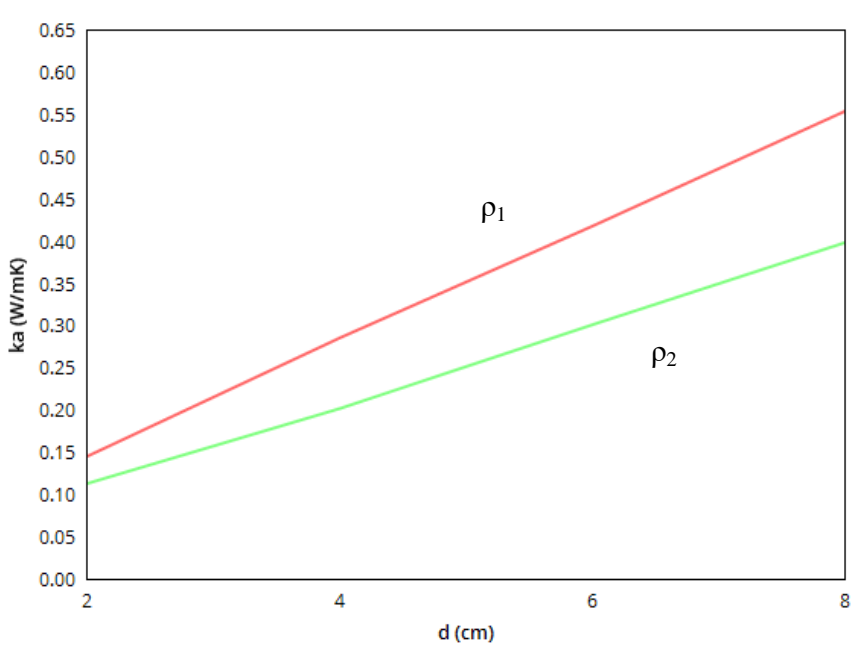

Fig. 5 Apparent thermal conductivity of sawdust with respect to thickness at $\rho_{1}=43.25 \mathrm{~kg} / \mathrm{m}^{3}$ and $\rho_{2}=64.875 \mathrm{~kg} / \mathrm{m}^{3}$

\section{Thermal Resistance of Sawdust}

Thermal resistances of sawdust, $\mathrm{R}$ at various thickness are shown in Fig. 6. The values of $\mathrm{R}$ increase along the thickness of sawdust. At $\rho_{1}=43.25 \mathrm{~kg} / \mathrm{m}^{3}$, values of thermal resistance increase from 0.1367 to $0.1446 \mathrm{~m}^{2} \mathrm{~K} / \mathrm{W}$, while $\mathrm{R}$ values increase from 0.1777 to $0.2011 \mathrm{~m}^{2} \mathrm{~K} / \mathrm{W}$ at $\rho_{2}=64.875$ $\mathrm{kg} / \mathrm{m}^{3}$. R values at $\rho_{2}=64.875 \mathrm{~kg} / \mathrm{m}^{3}$ are higher than those at $\rho_{1}=43.25 \mathrm{~kg} / \mathrm{m}^{3}$. At higher $\rho$ value, smaller porosity achieves for dense material and hence provides higher $\mathrm{R}$ values.

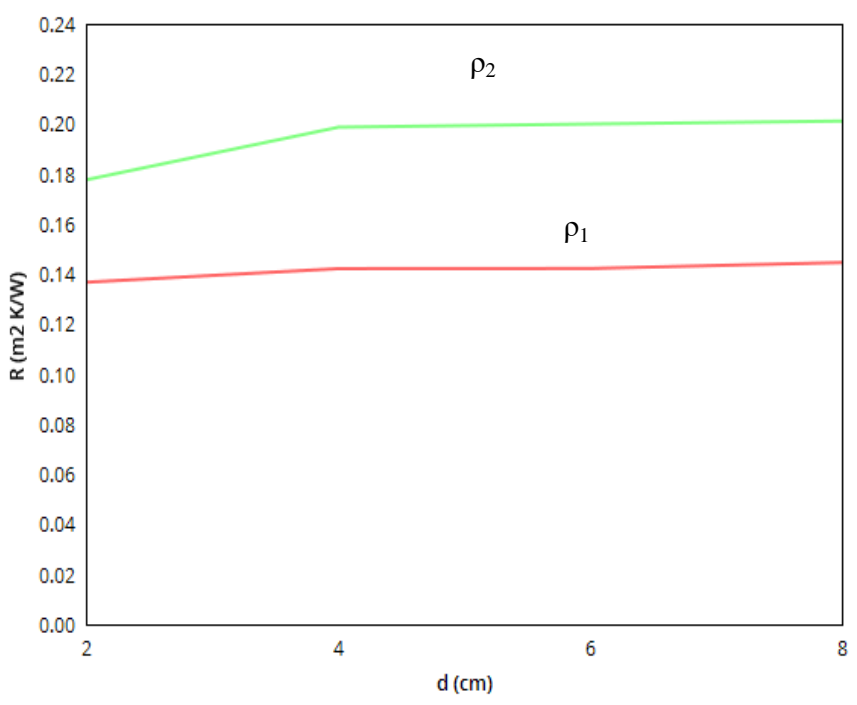

Fig. 6 Thermal resistance of sawdust with respect to thickness at $\rho=3.25$ $\mathrm{kg} / \mathrm{m}^{3}$ and $\rho=64.875 \mathrm{~kg} / \mathrm{m}^{3}$

\section{CONCLUSIONS}

The composition of $\mathrm{CaCO}_{3}$ effects burning path and burning time of sawdust specimen. The lowest burning path of $1.25 \mathrm{~cm}$ and burning time of 12 minutes achieved at $\mathrm{CaCO}_{3} 30 \%$. The apparent thermal conductivity of sawdust increases along with thickness. It is lower at $\rho_{2}=64.875$ $\mathrm{kg} / \mathrm{m}^{3}$ compared than those at $\rho_{1}=43.25 \mathrm{~kg} / \mathrm{m}^{3}$. R values increase with the thickness of sawdust specimen. $\mathrm{R}$ values are higher at $\rho_{2}=64.875 \mathrm{~kg} / \mathrm{m}^{3}$ compared than those at $\rho_{1}=$ $43.25 \mathrm{~kg} / \mathrm{m}^{3}$. 


\section{NOMENCLATURE}

d Thickness of sawdust

$\mathrm{cm}$

$d_{c} \quad$ Thickness of corrected polystyrene board

$\mathrm{m}$

$d_{p} \quad$ Thickness of corrected polystyrene board

$\mathrm{m}$

$\mathrm{k}_{\mathrm{a}} \quad$ Apparent thermal conductivity of sawdust

$\mathrm{W} / \mathrm{mK}$

$\mathrm{k}_{\mathrm{as}}$ Apparent thermal conductivity of polystyrene board

$\mathrm{W} / \mathrm{mK}$

$\mathrm{T}_{\mathrm{c}}$ Temperature at the bottom of polystyrene board ${ }^{\circ} \mathrm{C}$

$\mathrm{T}_{\mathrm{h}}$ Temperature at the top of polystyrene board ${ }^{\circ} \mathrm{C}$

$\mathrm{T}_{\mathrm{m}} \quad$ Average temperature of polystyrene board $\quad{ }^{\circ} \mathrm{C}$

$\mathrm{T}_{\mathrm{s}} \quad$ Temperature top of sawdust

${ }^{\circ} \mathrm{C}$

$\rho \quad$ Bulk density of sawdust

$\mathrm{kg} / \mathrm{m}^{3}$

$\mathrm{R}$ Thermal resistance $\mathrm{m}^{2} \mathrm{~K} / \mathrm{W}$

\section{ACKNOWLEDGMENT}

The authors thank Chemical Engineering Department Faculty of Engineering Sriwijaya University for the support of laboratory facilities during the research.

\section{REFERENCES}

[1] D.M.S. Al-Homoud, Performance characteristics and practical applications of common building thermal insulation materials, Builidng and Environment 40(3) (2005) 353 - 366.

[2] Florides GA, Tassou SA, Kalogirou SA, Wrobel LC, Measures used to lower building energy consumption and their cost effectiveness. Appl Energy 2002;73:299-328.

[3] C.Y. Jim, Air-conditioning energy consumption due to green roofs with different building thermal insulation, Applied Energy 128 (2014) 49-59.

[4] M. Hamdy, A. Hasan, K. Siren, Applying a multi-objective optimization approach for design of low-emission cost-effective dwellings, Building and Environment 46(2011)109-123.

[5] J. Damsky,J. Gero, An evolutionary approach to generating constraint-based space layout topologies, Proc. CAAD Future 1 (1997) 855-864.

[6] H. Islam, M. Jollands, S. Setunge, M.A. Bhuiyan, Optimization approach of balancing life cycle cost and environmental impacts on residential building design, Energy and Buildings 87(2015)282-292.

[7] A.M. Papadopoulos, State of the art in thermal insulation materials and aims for future developments, Energy and Buildings 37(2005)7786.

[8] B.C, Roberts, M.E. Webber, O.A, Ezekoye, O.A, Development of a multi-objective optimization tool for selecting thermal insulation materials in sustainable design, Energy and Builidings 105 (2015)358-367.
[9] L.FCabeza, Castell A, Medrano M, Martorell I, Perez G, Fernandez I, Experimental study on the performance of insulation materials in Mediterranean construction, Energy Build 2010;47:630-6

[10] A.M. Papadopoulos, State of the art in thermal insulation materials and aims for future developments, Energy Buildings 37(2005)77-86

[11] A.Fassi, Maina L, L'isolamento eco-efficente, 2nd ed. Milano; edizioni Ambiente; 2009

[12] R.W. Kessler, U. Becker, R. Kohler and, B. Goth, Steam explosion of flax-a superior technique for upgrading fibre value, Biomass Energy 14(3)(1998)237-249

[13] H.Y. Andoh, P. Gbaha, B.K. Koua, P.M.E. Koffi, S. Toure, Thermal Performance Study of a Solar Collector using a natural vegetable fiber, coconut coir, as heat insulation, Energy Sustain. Dev. 14 (2010)297-301

[14] M. Palumbo, J. Avellaneda, A.M, Lacasta, Availability of Crop byproducts in Spain: New raw material for natural thermal insulation, Resources, Conservation and Recycling 99 (2015)1-6

[15] S. Charca, J. Noel, D. Andia, J. Flores, A. Guzman, C. Renteros, J. Tumialan, Assessment of Ichu Fibers as non-expensive thermal insulation system for the Andean regions, Energy and Buildings 108 (2015)55-60

[16] S.V. Joshi, L.T. Drzal, A.K. Monanty, S. Arora, Are natural fiber composites environmentally superior to glass fiber reinforced composites: Part A 35 (2004)371-376.

[17] F. Ardente, Beccali M, Cellura M, Mistretta M, Building energy performance; ALCA case study of kenaf-fibres insulation board, Energy Build 2008;40:1-10

[18] GAFlorides, Tassou SA, Kalogirou SA, Wrobel LC, Measures used to lower building energy consumption and their cost effectiveness, Appl Energy 2002;73:299-328

[19] CABalaras, The role of thermal mass on the cooling load of buildings: an overview of computation methods, Energy Build 1996;24:1-10.

[20] E. D., Schmid, D. R. Salem, Fabrication technique and thermal insulation properties of micro- and nano-channeled polymer composites, Acta Astronautica 116 (2015) 68-73.

[21] L. Xu, Y. G. Jiang, J. Z. Feng, J. Feng, C. Yue, Infrared-opacified $\mathrm{Al}_{2} \mathrm{O}_{3}-\mathrm{SiO}_{2}$ aerogel composites reinforced by $\mathrm{SiC}$-coated mullite fibers for thermal insulations, Ceramic International 41 (2015) 437442 .

[22] Y. Hou, X. Cheng, S. Liu, C. Liu, H. Zhang, Experimental study on upward flame spread of exterior wall thermal insulation materials, Energy Procedia 66 (2015) $161-164$.

[23] R. Zahang, J. Feng, X. Cheng, L. Gong, Y. Li, H. Zhang, Porous thermal insulation materials derived from fly ash using a foaming and slip casting method, Energy and Buildings 81(2014) $262-267$.

[24] J.P. Hidalgo, S. Welch, J.L, Torero, Performance criteria for the fire safe use of thermal insulation in buildings, Construction and Building Materials 100(2015)285-297.

[25] M. Palumbo, J. Formosa, A.M. Lacasta, Thermal degradation and fire behaviour of thermal insulation materials based on food crop byproducts, Construction and Building Materials 79(2015)34-39.

[26] Suardana NPG, Ku MS, Lim JK, Effects of diammonium phosphate on the flammability and mechanical propoerties of bio-composites, Mater Des 2011;32:1990-9. 